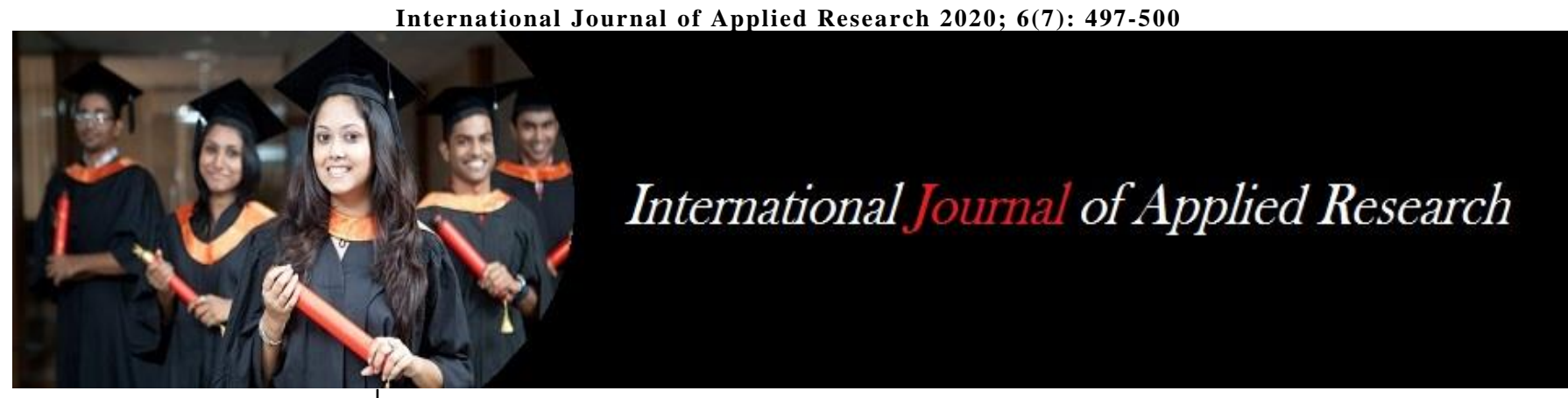

ISSN Print: 2394-7500 ISSN Online: 2394-5869 Impact Factor: 5.2 IJAR 2020; 6(7): 497-500 www.allresearchjournal.com

Received: 18-05-2020 Accepted: 22-06-2020

\section{Kavita Devi}

Nursing Tutor/Clinical Instructor, College of Nursing, IMS, BHU, Varanasi, Uttar Pradesh, India
Corresponding Author: Kavita Devi

Nursing Tutor/Clinical Instructor, College of Nursing, IMS, BHU, Varanasi, Uttar Pradesh, India

\title{
Level of anxiety, intensity of labour pain and duration of first stage of labour in the primigravida mothers
}

\section{Kavita Devi}

\author{
DOI: $\underline{\text { https://doi.org/10.22271/allresearch.2020.v6.i7g.6951 }}$
}

\section{Abstract}

Background: Labour is the most exciting and most painful situation for the women. A woman may feel happy and sad at one time. Happy feeling are due to the delivery of baby and sadness due to pain and prolong labour process. The purpose of this study was to assess the level of anxiety, intensity of labour pain and duration of first stage of labour in the primigravida mothers.

Objective: to assess the level of anxiety, intensity of labour pain and duration of first stage of labour in the primigravida mothers.

Methodology: Study was conducted in CLR, Nehru Hospital PGIMER Chandigarh, from 18th July to 8th September. Thirty nine primigravida mothers were selected by total enumeration sampling technique. The mother were introduced to the investigator and explained about the research project. The primigravida mothers was assessed for the level of anxiety and routine care was given. First assessment of labour pain was done at 3-4 cm. dilatation of cervix, second assessment done after 2 hours of first observation and third assessment was done after 2 hours of second observation in the subjects. Duration of active phase of first stage of labour was assessed by partograph from $3-4 \mathrm{~cm}$. to full dilatation of cervix.

Results: Average anxiety level should be in the range of 20-40 score of STAI Scale but Study result showed that there is high level of anxiety, in the range of 40-80. Intensity of labour pain measured by Numeric Pain Raiting scale (mild;1-3, moderate;4-6, and severe;7-10) intensity of labour pain was in the study subject mostly moderate $(61.5 \%)$ to severe $(33.3 \%)$ type of pain during first observation. and average duration of active phase of first stage of labour is 6 hours in primigravida mothers, study results showed $51.3 \%$ mothers had duration of 3-6 hours and $43.6 \%$ mothers had $>6$ hours of duration of active phase of first stage of labour.

Conclusion: Study concluded that high level of anxiety of primigravida mothers may increase the intensity of pain and also may increased the duration of labour. So nurses and other health personnel should give psychological support and explained the labour process to the primigravida mothers either before onset of labour or during antenatal.

Keywords: Primigravida mother, anxiety, labour pain

\section{Introduction}

Pregnancy and Childbirth is the special events to the mother and the family. Childbirth involves labour process and delivery of the baby. Labour is the series of events that take place in the genital organs in efforts to expel the viable fetus out of the womb through the vagina into external world ${ }^{[1]}$.

Labour pain is the unpleasant and distressing situation of the mother during the process of labour. It is a subjective and personal experience. There are many factors influencing the labour pain such as coping ability, sensitivity, past experience of pain, birth environment, psychological factors, etc. Labour pain is the most severe pain woman can experience throughout her life. Severity and duration of labour pain psychologically affect, a mother may lower the confidence, self-esteem and increase the level of anxiety ${ }^{[1]}$.

Anxiety is one of the factors that come with the labour pain or any other types of pain. It can occur with or without any cause. Mild anxiety is considered as normal but excessive anxiety and fear during labour increases catecholamine secretion, resulting in the mother to feel more pelvic pain ${ }^{[2]}$. 
A result of a survey of several investigations which included both primiparas and multiparas; shows that the incidence of intolerable pain ranged from $35 \%$ to $58 \%$ during labour. Another result found that $77 \%$ of primipara reported severe or intolerable pain during childbirth ${ }^{[3]}$.

\section{Objectives}

To assess the level of anxiety, intensity of labor pain, and duration of first stage of labor of primigravida mothers admitted at the CLR, Nehru Hospital, PGIMER, Chandigarh.

\section{Methods and Material}

This is descriptive type of study which was done at Clean Labour Romm, Nehru Hospital PGIMER, Chandigarh. Target population was primigravida mother admitted in the CLR, with 37 to 40 weeks of period of gestation. Total enumeration sampling technique used to draw the sample from 18th July to 8th September 2018. Sample size was 39 primigravida mother. In the Process of data collection, Prior permission was obtained from the Department of Obstetrics and Gynecology, PGIMER and on duty doctors were also informed. Investigator introduced herself to the participants and the objectives of the study were explained and written informed consent was taken from the primigravida mothers. This was divided into two phases (Identification and assessment phase). In Phase I:Identification of the primigravida mothers done By using socioeconomic and clinical profile proforma, primigravida mothers with gestational age of 37 to 40 weeks were identified during their admission at CLR. They were interviewed and their Sociodemographic Performa was filled by the investigator. In Phase II: Assessment; In this phase, follow up by investigator was done to assess the level of anxiety, intensity of labour pain and duration of active phase of first stage of labour. The investigator assessed the following parameters: A: Assessment of Anxiety: anxiety was assessed after introducing and explaining about the research project. B: Assessment of Pain: It was assessed using the Numeric Pain Scale after every 2 hours during active phase of first stage of labour 3 observations were made; 1 st observation done at 3 -
$4 \mathrm{~cm}$ dilatation of cervix, 2nd observation done after 2 hours of 1 st observation and 3rd observation done after 2 hours of 2nd observation. C: Assessment of Duration of first stage of labor: Duration of first stage of labour was assessed using the WHO partograph in primigravida mothers from $3-4 \mathrm{~cm}$ to full dilatation of cervix.

\section{Results}

Table 1 shows the absolute figures of the frequency and the percentage of those frequencies with respect to the total number of subjects. This table shows majority (53.8\%) of the women had age between 26-30 years in the subjects.

It also indicated that majority of the women were highly educated as $43.6 \%$ women were post graduates.

Seventy nine percentage of the women were housewives, making the majority among the study subjects.

Table 1: Socio demographic profile of the study subjects

\begin{tabular}{|c|c|}
\hline (Rupees) \$ & \multirow[b]{2}{*}{$11(28.2)$} \\
\hline$<5,000$ & \\
\hline $5,001-$ & $16(41.0)$ \\
\hline 10,000 & \multirow{2}{*}{$12(30.8)$} \\
\hline$>10,000$ & \\
\hline Marital status Married & $39(100)$ \\
\hline Family type & \multirow[b]{2}{*}{$15(38.5)$} \\
\hline Nuclear & \\
\hline Joint & $24(61.5)$ \\
\hline Residence & \multirow{2}{*}{$13(33.3)$} \\
\hline Rural & \\
\hline Urban & $26(66.7)$ \\
\hline
\end{tabular}

aMuslims and Christian, f- fisher's exact test \# Age in years (Mean $\pm \mathrm{SD})=26.51 \pm 3.341$, Range (20-36) \$Percapita income in rupees $($ Mean \pm SD $)=14857.92 \pm 25458.887$, Range $(1,000-20,0000)$

Table 2 shows the frequency of level of anxiety (state and trait anxiety) on the basis of mild (20-40), moderate (41-60) and severe (61-80).Majority of the primi mothers reported moderate anxiety $(84.9 \%)$. Majority of the mothers $(51.3 \%)$ showed mild trait of anxiety.

$\mathrm{N}=39$

Table 2: Frequency of anxiety level of the subjects using STAI (State and Trait Anxiety Inventory)

\begin{tabular}{|c|c|c|}
\hline \multirow{2}{*}{ Score for level of anxiety } & State anxiety & Trait anxiety \\
\hline & Subjects $(n=39) \mathbf{N}(\%)$ & Subjects $(n=39) n(\%)$ \\
\hline Mild (20-40) & $02(05.1)$ & $20(51.3)$ \\
\hline Moderate (41-60) & $32(82.1)$ & $19(44.2)$ \\
\hline Severe (61-80) & $05(12.8)$ & --- \\
\hline \multicolumn{2}{|l|}{ Variables } & $\operatorname{cts}(n=39)$ n $(\%)$ \\
\hline \multicolumn{2}{|l|}{ Age (in years) \# } & \multirow{2}{*}{$12(30.8)$} \\
\hline \multicolumn{2}{|l|}{$20-25$} & \\
\hline \multicolumn{2}{|l|}{$26-30$} & $21(53.8)$ \\
\hline \multicolumn{2}{|l|}{$>30$} & $06(15.4)$ \\
\hline \multicolumn{2}{|l|}{ Religion } & \multirow{2}{*}{$32(82.1)$} \\
\hline \multicolumn{2}{|l|}{ Hindu } & \\
\hline \multicolumn{2}{|l|}{ Sikh } & $07(17.9)$ \\
\hline \multicolumn{2}{|l|}{ Othersa } & - \\
\hline $\begin{array}{c}\text { Education } \\
\text { Secondary } \\
\text { Higher secondary } \\
\text { Graduate } \\
\text { Post graduate and abc }\end{array}$ & & $\begin{array}{l}01(02.6) \\
09(23.1) \\
12(30.8) \\
17 \quad(43.6)\end{array}$ \\
\hline $\begin{array}{c}\text { Occupation } \\
\text { Housewife } \\
\text { Governmen } t \text { servic } \\
\text { Private service }\end{array}$ & & $\begin{array}{l}31(79.9) \\
01(02.6) \\
07(17.9)\end{array}$ \\
\hline
\end{tabular}




\begin{tabular}{|c|c|}
\hline No. of family & $05(12.8)$ \\
\hline members & $12(30.8)$ \\
\hline 2 & $12(30.8)$ \\
\hline $3-4$ & $09(25.6)$ \\
\hline $5-6$ & \\
\hline$>6$ & \\
\hline Percapita income (in) & \\
\hline
\end{tabular}

Frequency and percentage of intensity of labour Pain of the subjects using Numeric Pain Rating Scale

Assessment of pain done by rating the *numbers from " 0 " to "10". No pain (0 score), mild pain (1-3 score), moderate pain (4-6 score), severe pain (7-10 score). Higher score indicated greater pain intensity.

Figure 1: Frequency and percentage of intensity of labour Pain of the subjects during 1st observation

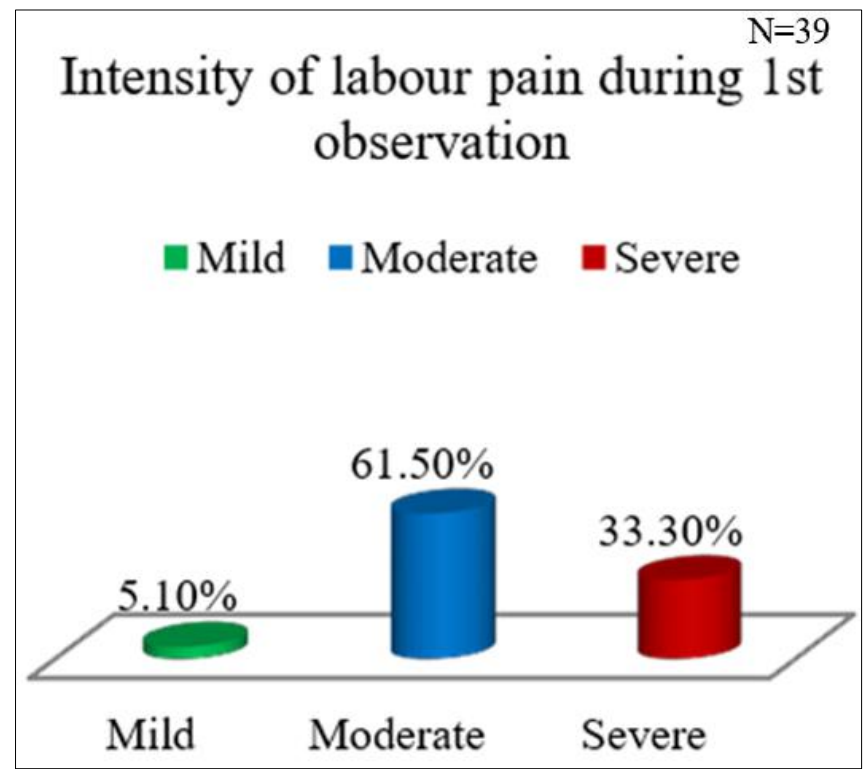

Fig 1: Intensity of labour pain during 1st observation

Figure 1 revealed that majority $(61.5 \%)$ of the mothers felt moderate pain

Figure 2: Frequency and percentage of intensity of labour Pain of the subjects in 2nd observation

\section{$\mathrm{N}=39$}

\section{Intensity of labour pain during 2nd observation}

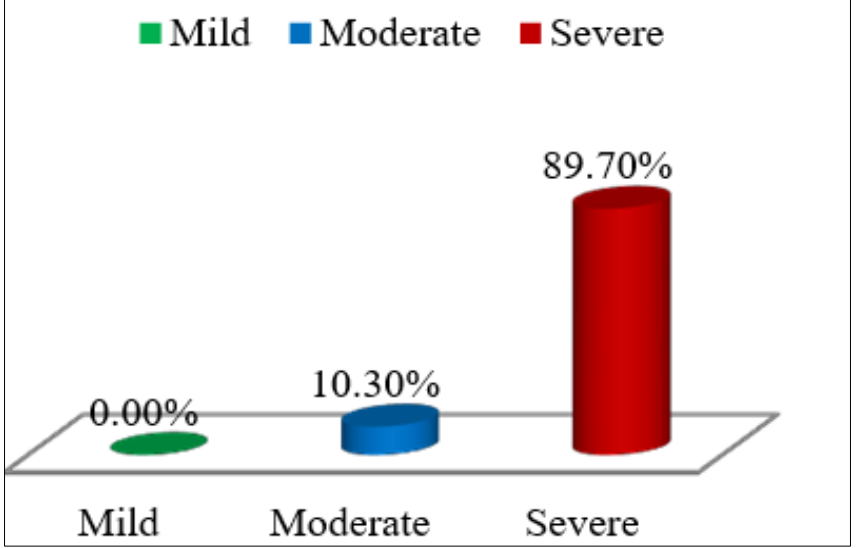

Fig 2: Intensity of labour pain during 2nd observation
Figure 2 shows that $89.7 \%$ mothers were felt severe pain. Figure 3: Frequency and percentage of intensity of labour Pain of the subjects during 3rd observation

\section{Intensity of labour pain during 3rd observation

\section{Mild $\square$ Moderate $\square$ Severe}

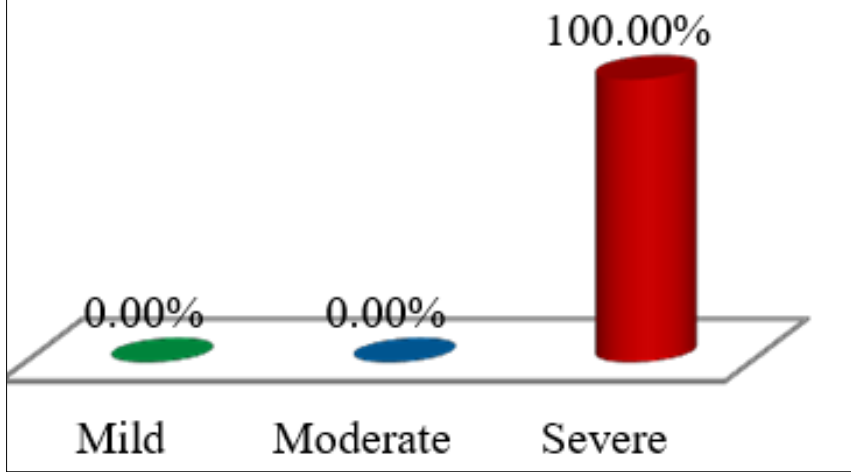

Fig 3: Intensity of labour pain during 3rd observation

Figure 3 depicts that all mothers (100\%) reported severe type of labour pain.

Figure 4: Frequency (in percentage) of duration for active phase of first stage of labour in the primigravida mothers Figure 4 shows the frequency of duration $(<3,3-6$ and $>6$ hours) of active phase of first stage of labour in the primi mothers. Majority of the mothers (51.3\%) had between 3-6 hours of duration of active phase of first stage of labour.

\section{Frequency of duration for active phase} of first stage of labour

$$
\square<3 \text { hours } \square 3-6 \text { hours } \square>6 \text { hours }
$$

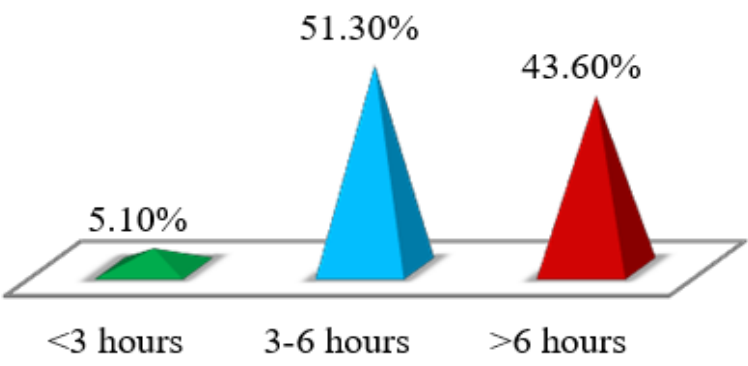

Figure 4: Frequency of duration for active phase of first stage of labour

Mean \pm SD $(4.36 \pm 1.85$ hours), Range (1-7 hours) 


\section{Discussion}

Most of the mother feel excitement as well as fearful feeling during labour. They are having happy and sad feeling at same time, fear and anxiety may affects on the intensity of labour pain and length of duration of active phase of first stage of labour.

Anxiety is one of the factors that come with the labour pain or any other types of pain. It can occur with or without any cause. Mild anxiety is considered as normal but excessive anxiety and fear during labour increases catecholamine secretion, resulting in the mother to feel more pelvic pain ${ }^{[2]}$. A result of a survey of several investigations which included both primiparas and multiparas; shows that the incidence of intolerable pain ranged from $35 \%$ to $58 \%$ during labour. Another result found that $77 \%$ of primipara reported severe or intolerable pain during childbirth ${ }^{[3]}$.

This is descriptive type of study done in the primigravida mother with 37 to 40 weeks of period of gestation. Total enumeration sampling technique used to draw the sample from population. There are two phases first phase Identification of primigravida mothers and second phase assessment of level of anxiety, intensity of labour pain and duration of active phase of first stage of labour.

Present study showed that more than $2 / 3$ rd $(82.1 \%)$ subjects expressed moderate level of anxiety.

A study supported by Nisha Walia which was conducted in 2013 on to assess the level of anxiety during labour process in primigravida mothers. Results showed that the the majority of the primigravida i.e. $79 \%$ had moderate level of anxiety, $14 \%$ of primigravida had mild level of anxiety and $7 \%$ of them expressed severe type of anxiety ${ }^{[4]}$.

In the present study during first observation of labour pain more than $1 / 2$ of the primi mother expressed moderate pain, during 2nd observation more than $2 / 3$ rd mother expressed severe pain and during 3rd observation all mothers expressed severe pain. so labour pain is the most severe pain which is experience by women in their life.

A qualitative study supported which was done by Nastaran Mohammad Ali Beigi, et al. in 2010. This study was done by the interview with 14 help seekers who were hospitalized in the postpartum wards of Isfahan hospitals. Among all of the participants, 9 of them had their first delivery, 4 and one had their second and fifth delivery, respectively and all of them were aged between $18-35$ years ${ }^{[5]}$.

Nature of labor pain is consisted of two sub-concepts of "severity and type of the pain" and "feelings accompanied with labor pain". Help seekers' experience of severity and type of the pain was described as, "delivery pain is really hard to endure, it is not similar to other pains ... the most severe pain that I've ever tolerated was labor pain", told by one of the participants.

And also "its pain is unbearable and indescribable" was said by another participant.

To describe the type and location of the pain another participant said, "I had pain during my menstruation; its pain was like that but 10 times more".

The median duration of active phase of first stage of labour in present study was 3- 6 hours. One of the study supported the present study which was done by Edgardo Abalos et al. in 2018. Their study result showed the median duration of active first stage (when the starting reference point was $4 \mathrm{~cm}$ ) ranged from 3.7-5.9 $\mathrm{h}$ (95th percentiles: 14.5-16.7 h). With active phase starting from $5 \mathrm{~cm}$, the median duration was from 3.8-4.3 $\mathrm{h}$ (95th percentiles: $11.3-12.7 \mathrm{~h})^{[6]}$.

\section{Conclusion}

Labour is very sensitive phase of a women, and fear and anxiety may be high in primi mothers during process of labour, and also it affects the duration of labour and intensity of pain perception during labour.

\section{Recommendation}

To assess the effectiveness of non- pharmacological intervention on the level of anxiety, intensity of pain and duration of active phase of first stage of labour.

To assess the effectiveness of non- pharmacological intervention on the duration of first and second stage of labour.

\section{References}

1. Dutta D C. Textbook of Obstetrics.7th edition. Delhi: New Central Book Agency (P) ltd. 2008; 113:117-118.

2. Crandon. Maternal anxiety and obstetrics. Journal of Psychosomatic Research. [online] 1979. [cited 2 February 2018; 29(23):109. Available from https://www.ncbi.nlm.nih.gov/pub med/314979

3. Laesser JP, Bonika JJ. Bonica management: 3rd edition. Steph am- medicine.com/tag/bonicas_manage ment_of_pain_3rd_edition_pdf_fre e_download

4. Walia N. Ramanadin P.V. and Kiran. Asian Journal of Nursing Education and Research. To assess the level of anxiety during labour in primigravida mothers. [online] 2013. 2018; (3):273-275. Available from https://www.ajner.com.

5. Ali Beigi NM, Broumandfar K, Bahadoran P, Ali Abedi H. Women's experience of pain during childbirth. Iran J Nurs Midwifery Res. [online] 20102018; 15(2):77-82. Available from https://www.ncbi.nlm.nih.gov/pmc/ articles/PMC3093177/.

6. Abalos E, Olufemi T, Chamillard OM, Díaz V, Pasquale J, Bonet $\mathrm{M}$ et al. Duration of spontaneous labour in 'low-risk' women with 'normal' perinatal outcomes: A systematic review. European Journal of Obstetrics and Gynaecology and Reproductive Biology. [online] 2018. [cited 19 June 2018]; volume 223 123132. Available from https://www.ejog.org/article/S0301-2115(18)300824/fulltext. 